\title{
Seroma, CTCAE
}

National Cancer Institute

\section{Source}

National Cancer Institute. Seroma, CT CAE. NCI Thesaurus. Code C58401.

A finding of tumor-like collection of serum in the tissues. 